\title{
Immune Cell Subtypes and Their Function in the Testis
}

\begin{abstract}
Sudhanshu Bhushan ${ }^{1,2 *}$, María S. Theas ${ }^{3,4}$, Vanesa A. Guazzone ${ }^{3,4}$, Patricia Jacobo $^{3,4}$, Ming Wang ${ }^{5}$, Monika Fijak ${ }^{1,2}$, Andreas Meinhardt ${ }^{1,2}$ and Livia Lustig ${ }^{3,4 *}$

1 Department of Anatomy and Cell Biology, Justus-Liebig University Giessen, Giessen, Germany, ${ }^{2}$ Hessian Center of Reproductive Medicine, Justus-Leibig-University Giessen, Giessen, Germany, ${ }^{3}$ Departamento de Biología Celular e Histología/Unidad Académica II, Facultad de Medicina, Universidad de Buenos Aires (UBA), Buenos Aires, Argentina, ${ }^{4}$ Consejo Nacional de Investigaciones Científicas y Técnicas (CONICET), Facultad de Medicina, Instituto de Investigaciones Biomédicas (INBIOMED), Universidad de Buenos Aires (UBA), Buenos Aires, Argentina, ${ }^{5}$ Medical Research Center, The First Affiliated Hospital of Zhengzhou University, Zhengzhou, China
\end{abstract}

OPEN ACCESS

Edited by:

Kenneth Tung,

University of Virginia, United States

Reviewed by:

Tony DeFalco,

Cincinnati Children's Hospital Medical

Center, United States

Suresh Yenugu,

University of Hyderabad, India

Emily Bryan,

Queensland University of Technology,

Australia

${ }^{*}$ Correspondence:

Livia Lustig

livialustig38@yahoo.com.ar

Sudhanshu Bhushan

sudhanshu.bhushan@

anatomie.med.uni-giessen.de

Specialty section: This article was submitted to

Mucosal Immunity,

a section of the journal

Frontiers in Immunology

Received: 14 July 2020 Accepted: 14 September 2020 Published: 30 September 2020

Citation:

Bhushan S, Theas MS, Guazzone VA, Jacobo $P$, Wang $M$, Fijak $M$,

Meinhardt $A$ and Lustig L (2020)

Immune Cell Subtypes and Their

Function in the Testis.

Front. Immunol. 11:583304. doi: 10.3389/fimmu.2020.583304
Immunoregulation in the testis is characterized by a balance between immunosuppression (or immune privilege) and the ability to react to infections and inflammation. In this review, we analyze the phenotypes of the various immune cell subtypes present in the testis, and how their functions change between homeostatic and inflammatory conditions. Starting with testicular macrophages, we explore how this heterogeneous population is shaped by the testicular microenvironment to ensure immune privilege. We then describe how dendritic cells exhibit a tolerogenic status under normal conditions, but proliferate, mature and then stimulate effector T-cell expansion under inflammatory conditions. Finally, we outline the two T-cell populations in the testis: $\mathrm{CD} 4^{+} / \mathrm{CD}^{+} \alpha \beta \mathrm{T}$ cells and $\mathrm{CD}^{+} / \mathrm{CD}^{+}{ }^{+}$Foxp $^{+}$regulatory $T$ cells and describe the distribution and function of mast cells. All these cells help modulate innate immunity and regulate the immune response. By improving our understanding of immune cell behavior in the testis under normal and inflammatory conditions, we will be better placed to evaluate testis impairment due to immune mechanisms in affected patients.

Keywords: testis, immune privilege, macrophages, dendritic cells, T lymphocytes, mast cells

\section{INTRODUCTION}

The mammalian testis is divided into two main compartments: the convoluted seminiferous tubules, where spermatogenesis occurs, and the interstitial space where Leydig cells (LC) produce the male sex hormones (androgens). During spermatogenesis, germ cells divide and mature in close association with somatic Sertoli cells (SC) that extend from the basal membrane to the tubule lumen. Multiple highly specialized cell junctions namely tight, adherens and gap junctions extend between neighboring SC to form a blood-testis-barrier (BTB) that is permissive to the developing germ cells. Bordering the SC and spermatogonia, a basement membrane containing extracellular matrix proteins and a contractile peritubular cells (PTC, also known as myoid cells) sheet divides the seminiferous epithelium from the interstitium. Organization of the PTC sheet varies by species; in rodents, only one PTC layer is seen whereas in humans it typically consists of 5-7 layers (1). Immune cells in the testis are found exclusively in the interstitium, in close association with either PTC or LC, as well as with lymphatic and blood vessels (Figure 1). Some authors described that in rodents lymphatic vessels are restricted to the tunica 


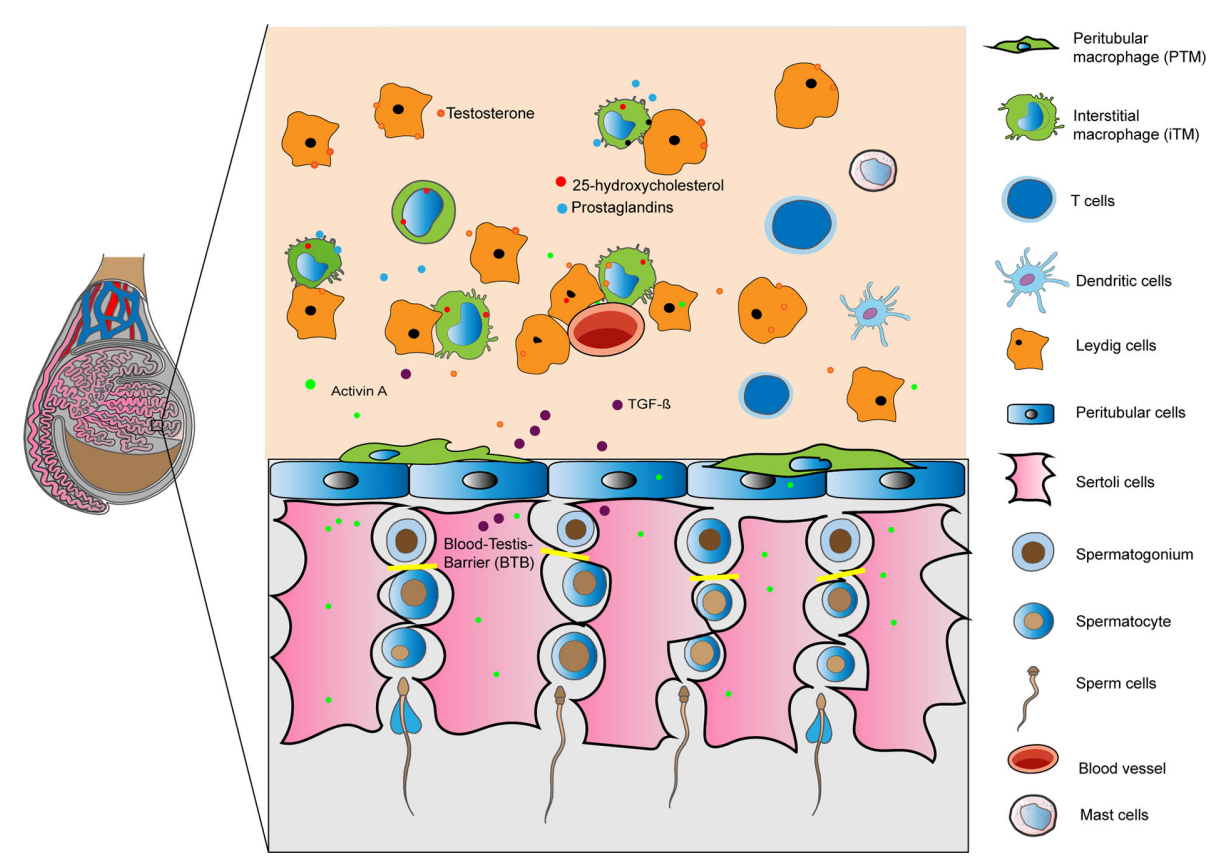

FIGURE 1 | Immunoregulation of the testis is mediated by a combination of structural (blood- testis barrier) and cellular derived factors. Illustration shows in a rodent testis, resident macrophages, tolerogenic dendritic cells, T cells and mast cells in the interstitium interacting with Leydig, Sertoli and peritubular cells releasing factors to create an optimal microenvironment for germ cells. Under inflammatory conditions immune cells are able to respond to invading pathogens.

albuginea (2-4), while others reported irregular channels incompletely bound by endothelial cells (5). In contrast, Kitadate et al. (6) described in mice testis parietal lymphatic endothelial cells (LE) that cover the surface of lymphatic space, mainly in the peritubular area close to the PTC layer contributing to the spermatogenic stem cell niche homeostasis through the supply of fibroblast growth factor ligands secreted by LE cells (6). Telocytes, a stromal cell type similarly localized as LE cells, have been recently identified in rodent and human testis $(7,8)$. It has been suggested a possible role of telocytes in the regulation of lymphatic capillary function (9). The immunomodulatory factor secreted by immune cells, and somatic cells (LC, SC, and PTC), in combination with BTB, forms a unique immunological environment that: (i) protects immunogenic germ-cell-specific neoantigens and transplants from immune attack, and (ii) responds to invading pathogens by eliciting a delicately balanced immune response to protect sensitive germ cells $(10,11)$.

The functions of the BTB, SC, LC, and PTC in preserving the immune privileged status of the testis has been described in details in previous reviews $(11,12)$. As such, we rather describe the different immune cells of the testis that maintain the immune privileged status and contribute to the immune response against inflammatory stressors.

\section{MACROPHAGES}

In the broadest sense, macrophages constitute an immune cell population with phagocytic characteristics, ingesting foreign particles and invading pathogens such as bacteria, and clearing cell debris. Given their essential role, macrophages are found in all mammalian organs where they perform immune and nonimmune functions (13). As is the case for other organs, macrophages are by far the most abundant and heterogeneous immune-cell population found in the testis $(14,15)$. The heterogeneity of these tissue-resident macrophages has been delineated based on cell surface marker expression, anatomical localization, gene expression profiles, ontogeny, and post-natal development. Under normal conditions, most testicular macrophages (TM) express the core macrophage markers F4/ $80, \mathrm{CD} 11 \mathrm{~b}, \mathrm{AIF}$, and CX3CR1 $(4,16)$. The heterogeneity of the macrophages is evidenced by the differential expression of surface markers CD64 and major histocompatibility complex class II (MHC II), besides their localization relative to other cells within the testis $(4,16)$.

Under steady conditions, interstitial (iTM) and peritubular (pTM) macrophages predominate (16). iTM are characterized by $\mathrm{CD}^{\mathrm{hi}} \mathrm{MHC}^{\text {lo }}$ expression and are found adjacent to LC and blood vessels (Figure 1) $(4,16)$. By contrast, pTM are characterized by $\mathrm{CD} 64^{\mathrm{lo}} \mathrm{MHC}{ }^{\text {hi }}$ expression and are found adjacent to the seminiferous tubules (Figure 1) $(4,16)$. Each TM subpopulation also expresses a unique transcriptional profile, which is indicative of functional specialization. For example, CD64 ${ }^{\text {lo }} \mathrm{MHC}^{\text {hi }}$ pTM express high levels of antigen presentation genes, such as genes encoding the MHCII $\mathrm{H} 2 \mathrm{Dmb}, \mathrm{H} 2 \mathrm{~Eb} 1$, and, H2K1. Conversely, CD $64^{\text {hi }} \mathrm{MHC}^{\mathrm{lo}} \mathrm{pTM}$ express high levels of immunosuppressive genes, namely, IL10 and Marco (16). 
A recent study used single-cell mRNA sequencing (scRNAseq) to identify two interstitial macrophage sub-populations of the lung, which were also found in the testis: Lyve $1^{\text {lo }} \mathrm{MHCII}{ }^{\text {hi }}$ and Lyve $1^{\text {hi }} \mathrm{MHCII}^{\text {lo }}$. These two subpopulations are distinct in localization, phenotype, and gene expression (17). Although TM seem to comprise only two main subsets, in-depth analyses using scRNA-seq and high powered confocal microscopy are needed to characterize the extent of heterogeneity in detail.

Resident macrophages in the brain, liver, and lung that arise embryonically either from the yolk sac or fetal liver; are maintained locally by self-renewal in adult life without notable contribution from blood monocytes (18). In other organs, such as the intestine, dermis, and pancreas, macrophage populations are maintained by replacement from blood monocytes (19-22). However, the exact contribution of embryonic progenitors and blood monocytes that give rise to tissue-resident macrophages in adult life is still controversial. Moreover, the mechanism by which adult tissue resident macrophages maintained in adult life is not yet completely understood.We have made great progress in recent years to unravel the ontogeny and functional heterogeneity of macrophage population in different organs, the origins of TM are still unclear. iTM are thought to originate from embryonic progenitors, whereas pTM seem to arise postnatally from bone marrow derived cells (16); however, the relative contributions of embryonic progenitors to the adult TM and the mechanisms of TM maintenance in adulthood are undefined.

Although all tissue-resident macrophages arise from distinct cellular origin, (23) upon organ entry, tissue-specific signals polarize macrophages to endow them with tissue- specific functions (24). For example, the intranasal transfer of progenitors from either the yolk sac, fetal liver, or bone marrow to the lungs of $C s f 2 \mathrm{rb}^{-/-}$mice lacking adult alveolar macrophages resulted in the polarization of macrophage progenitors with functional and transcriptional properties reminiscent of alveolar macrophages. These findings suggest that intrinsic factors rather than cellular origins, might imprint the resident macrophage phenotype (25). The testis microenvironment contains numerous immunomodulatory molecules - namely testosterone, prostaglandins, corticosterone, activin, and 25 hydroxy-cholesterol $(25 \mathrm{HC})$ - that might govern TM phenotype and function (Figure 1) $(14,26)$. Indeed, we found that testosterone, prostaglandins, and corticosterone present in the testicular interstitial fluid can polarize GM-CSF-derived macrophages to immunosuppressive macrophages by inducing CD163 and IL10 expression with concomitant low TNF- $\alpha$ production (14). Other molecules, such as $25-\mathrm{HC}$ and activin, are also produced in large amounts in the testis $(26,27)$. Whether these molecules can influence TM phenotype and function has not been investigated, we speculate that they likely have a role.

Recent data primarily from in vitro studies suggest a role for TM in maintaining the immune privileged state of the testis $(28,29)$. Specifically, TM exhibit anergy to inflammatory stimuli, which serves to protect developing germ cells from the deleterious effects of pro-inflammatory cytokine. The mechanisms underlying this subdued inflammatory response of TM could be based on the low expression of toll like receptor
(TLR) signaling genes and impaired ubiquitination and degradation of the NF- $\mathrm{kB}$ inhibitor $\mathrm{I} \mathrm{kB} \alpha$ that ultimately inactivates the inflammatory NF-kB signaling pathway (28).

TM are immunoregulatory, secreting high levels of IL10, and producing low levels of TNF- $\alpha$ and nitric oxide (NO) upon stimulation with the TLR4 ligand, lipopolysaccharide (LPS) (28, 29). In addition, TM suppress T-cell proliferation and activation, and induce naive $\mathrm{T}$-cell differentiation into immunosuppressive regulatory $\mathrm{T}$ cells (Tregs) $(14,29)$. The TM immunoregulatory phenotype seems to be essential to preserve normal testis homeostasis: high TNF- $\alpha$ production impairs LC function and can breakdown the BTB, exposing the germs cell to cytotoxic inflammatory cytokines that ultimately impairs spermatogenesis (30). High NO production can also negatively affect LC function and consequently, steroidogenesis (31).

Besides acting as immune sentinel cells, TM are also equipped to perform testis-specific functions to maintain normal homeostasis, including: (1) supporting steroidogenesis by producing $25 \mathrm{HC}$, (2) promoting spermatogenesis by expressing sp?A3B2 ? >ermatogonial proliferation- and differentiation-inducing factors such as colony stimulating factor 1 (CSF1) and enzymes involved in retinoic acid (RA) biosynthesis, and (3) guiding testis embryonic development by aiding blood vessel and spermatic cord formation $(4,26)$.

The number of TM increases during testis inflammation, as observed following acute LPS stimulation or in experimental models of murine chronic autoimmune epididymo-orchitis (EAO) induced by immunization with testis homogenate and adjuvants or pathogen-induced (E. coli) inflammation (epididymo-orchitis) (32-35). During LPS-induced inflammation, a transient influx of monocytes into the testis occurs that resolves after $72 \mathrm{~h}$; whereas no changes in the number of TM was observed (32). Similarly, following E. coli-induced epididymo-orchitis, inflammation in the testis quickly resolves after the initial infiltration of immune cells and impairment of spermatogenesis. However, without therapeutic intervention, inflammation of the epididymis continues to remain (35). These observations suggest that the testis has a remarkable ability to resolve inflammation via mechanisms likely involving TM. Now, further studies are required to investigate how TM resolve inflammation and promote tissue repair.

We have gained mechanistic detail underlying the role of TM in resolving inflammation from the experimental autoimmune orchitis (EAO) model. Here, the number of TM subsets $\mathrm{CD}^{+} 8^{+} \mathrm{CD} 163^{-}$and $\left(\mathrm{CD} 68^{+} \mathrm{CD} 163^{+}\right)$increases progressively from the end of the immunization period to the severe orchitis stage, with minor changes in the number of resident $\mathrm{CD} 163^{+} \mathrm{TM}$ (33). At the same time, TM release large amounts of the pro-inflammatory mediators TNFo, IL6, IFN $\gamma$, and NO but not IL10 and GM-CSF $(33,36,37)$. Infiltrating macrophages, but not resident $\mathrm{CD}_{163}{ }^{+}$ TM, express IL6, upregulate MHCII and reduce TNF $\alpha$ expression (33). Neither infiltrating $\left(\mathrm{CD} 8^{+} \mathrm{CD} 163^{-}\right)$, intermediate $\left(\mathrm{CD}^{+} 8^{+} \mathrm{CD} 163^{+}\right)$nor resident $\left(\mathrm{CD}^{-} 8^{-} \mathrm{CD} 163^{+}\right)$TM up-regulate iNOS expression during EAO (37). The increase in NO production by TM during EAO mainly results from the large percentage of infiltrating and intermediate TM expressing iNOS; resident TM 
contribute to NO production to a lesser extent. These events, as well as changes in other immune and nonimmune cell functions, ultimately disrupt testicular immune privilege and impair spermatogenesis and steroidogenesis (38).

The consequences of perturbed TM function are evident in infertile patients with hypospermatogenesis and Sertoli cellonly syndromes. Namely, patients present with an increased level of the TM-derived pro-inflammatory cytokines TNF $\alpha$, $\operatorname{IL} 1 \alpha$, and $\operatorname{IL} 1 \beta(39,40)$. Interstitial infiltration of activated macrophages and TNF $\alpha$ production is also a common feature in other models of testicular damage, such as testicular torsion (41), and in two models of transgenic male mice, one ectopically expressing humanP450 aromatase (AROM+), and the Tyro3, Axl and Mer (TAM) receptor tyrosine kinase triple knockout (42).

\section{DENDRITIC CELLS}

Dendritic cells (DC) are "professional" antigen-presenting cells and a cellular component of the adaptive immune system. DC constitute a heterogeneous population that includes classical DC, plasmacytoid DC, and monocyte-derived DC originating from hematopoietic stem cells in the bone marrow. DC are found in lymphoid and nonlymphoid tissues and have a role in T-cell activation and tolerance induction, both of which depend on many environmental signals (43). We found that normal rat testis and testicular draining lymph nodes (TLN) contain $\mathrm{CD}_{103^{+}} \mathrm{DC}$ that express MHCII and B7 costimulatory molecules. However, functional data from in vitro assays revealed that these DC are unable to stimulate naïve T-cell proliferation $(36,44,45)$. This finding suggests that DC support the immune privilege status of the testis as they adopt a tolerant status in the physiological testicular microenvironment.

DC isolated from normal testis also express the chemokine receptor CCR2, which is a marker of immature resident DC. Gao et al. showed that Sertoli cells may promote the differentiation of these immature DC into tolerogenic DC since mice prepuberal Sertoli cell-conditioned of mice DC down-regulate the expression levels of costimulatory molecules and decrease T-cell priming (46).

During EAO, $\mathrm{CD}_{103}{ }^{+} \mathrm{MHCII}^{+} \mathrm{CD}^{+}{ }^{+} \mathrm{CD}^{+}{ }^{+} \mathrm{DC}$ isolated from the testis and TLNs can activate $\mathrm{T}$ cells and produce IL12p70 $(44,45)$. Bioactive IL12p70 can bias activated T cells in favor of an inflammatory Th1 response (47). Moreover, DC isolated from EAO testes show an upregulation of chemokine receptor CCR7 expression, which directs DC migration to the TLN (45). In fact, mature $\mathrm{CD}_{103}{ }^{+} \mathrm{DC}$ accumulate in the lymph nodes (LN) that drain the EAO testis (44).

Based on our knowledge in the rat model thus far, we propose a putative model by which $\mathrm{CD}_{103^{+}}$DC promote the induction and progression of orchitis. In the LN draining the immunization site, DC present orchitogenic antigens on their surface in the context of MHCII, then prime naïve T cells and polarize them toward effector functions. DC-sensitized T cells migrate to the testis, where they are attracted by local chemokines (CCL2 and CCL3) secreted by antigen presenting cells and somatic cells and contribute to testicular inflammation causing tissue damage $(48,49)$. Testicular DC take up spermatic antigens from the impaired seminiferous tubules to undergo immunogenic maturation, and subsequently travel to the TLN via the lymphatic system; alternatively, they might prime naïve $\mathrm{T}$ cells in situ. Consequently, this process would increase manifold in response to inflammatory signals leading to chronic orchitis.

\section{LYMPHOCYTES}

Depending on environmental signals, $\mathrm{T}$ cells commit to effector or regulatory lineages with opposing functions leading to inflammation or dominant immunologic tolerance (50). Flow cytometric analysis of the leukocytes present in the normal rat testis showed that nearly $25 \%$ of these cells are $\mathrm{CD}^{+} \mathrm{T}$ cells, and that the percentage of $\mathrm{CD}^{+} \mathrm{T}$ cells is 4 -fold greater than that of $\mathrm{CD} 4^{+} \mathrm{T}$ cells. Most $\mathrm{CD} 25^{+} \mathrm{T}$ cells are found within the $\mathrm{CD} 8^{+}$ subset (51). Both subsets express proinflammatory mediators, such as TNF $\alpha$, IFN $\gamma$, and FasL. A similar percentage of cells within the $\mathrm{CD}^{+}$and $\mathrm{CD} 8^{+} \mathrm{T}$ cell subsets express IFN $\gamma$; however, $\mathrm{CD}^{+} \mathrm{T}$ cells are the main producers of FasL and TNF $\alpha$. Testicular $\mathrm{T}$ cells expressing IL4 are occasionally observed under normal conditions $(52,53)$.

The presence of Foxp $3^{+}$Tregs in the normal testis is well established (54-56). In the rat testis, $\sim 2 \%$ of the cells within the $\mathrm{CD}^{+}$and $\mathrm{CD} 8^{+}$T-cell subsets express CD25 and Foxp3 (51). This percentage rises to $4 \%$ in the TLN (57). Most of these cells show a memory phenotype and produce TFG- $\beta$. Functional analysis of $\mathrm{CD}^{+} \mathrm{CD} 25^{+} \mathrm{Foxp}^{+}$Tregs isolated from the TLN showed that these cells produce a potent proliferative response toward spermatic antigens and exert suppressive effects that prevent conventional T-cell proliferation (57). These results support that Tregs are activated in vivo by antigens from the seminiferous tubules. In fact, Tung et al. demonstrated that non sequestered germ cell antigens egressed from seminiferous tubules, enter the interstitium, and induce Tregs challenging the long-standing dogma that all germ cell neo-antigens are sequestered from the immune system (58). These phenomena elicit the expansion of Tregs in the TLN, where they may exert a basal and permanent suppression of auto-reactive $\mathrm{T}$ cells, thereby maintaining the tolerogenic environment $(57,58)$.

Under inflammatory conditions, pathogenic $\mathrm{T}$ cells can overwhelm the suppressive mechanisms of Tregs by altering the balance in favor of an autoimmune response (51). For example, during EAO, $\mathrm{CD}^{+}$, and $\mathrm{CD}^{+} \mathrm{T}$ cells producing TNF- $\alpha$, IFN $\gamma$, and FasL infiltrate the testis. Th1 and Th17 subsets serve as co-effector cells that govern the early stages of the disease whereas $\mathrm{CD}^{+} \mathrm{T}$ cells producing Th1 and Th17 cytokines are relevant to establish chronic inflammation (51-53). Although Tregs accumulate in the testis and in the TLN, and despite that Tregs from the TLN are more effective at suppressing T-cell proliferation than their normal counterparts, these Tregs are unable to prevent germ cell attack. One proposal for this 
paradigm is that cytokines in the inflammatory milieu might inhibit Tregs in vivo, compromising their function at inflammation sites $(56,57)$.

\section{MAST CELLS}

Mast cells (MC) are tissue resident immune cells with heterogeneous phenotypes localized within the subalbuginea area near blood vessels in rodents and/or in the interstitial compartment in humans (Figure 1). MC derive from CD $34^{+}$ hematopoietic progenitor cells, differentiating initially in the bone marrow and then locally in the specific organ that they have migrated to under the influence of estrogens (59). MC have diverse roles in innate immunity, tissue homeostasis and remodeling, and adaptive immunity. Pre-synthesized substances such as histamine, chymase, tryptase, carboxipeptidase $\mathrm{A}$, and $\mathrm{TNF} \alpha$ are stored in granules and are released immediately after MC activation (60). TNF $\alpha$, IL6, and IL1 $\beta$ are synthesized de novo after MC activation (61). Direct interactions with autoreactive $\mathrm{T}$ cells may activate $\mathrm{MC}$, inducing degranulation, and cytokine production.

During inflammation (such as in patients with defective spermatogenesis, varicocele, infertility, or EAO and testis torsion models) the number of MC increases. Here, the serine protease tryptase enhances fibroblast proliferation and collagen synthesis, inducing fibrosis of the seminiferous tubules (62). MC might also regulate fibrosis by activating matrix metalloproteinases (MMP) and tissue MMP inhibitors (63).

In the EAO model, MC mainly accumulate around the ST and especially the surrounding granulomas (64). Tryptase released by these MC activates proteinase-activated receptor-2 (PAR2) that is expressed by peritubular cells and TM to induce cell proliferation and cytokine production (64). Moreover, PAR2-derived peritubular cells drive an increase in the expression of inflammatory mediators MCP1, TGF 32 , and cyclooxygenase COX2.

Analyses of human testis biopsies from infertile patients found an increase in the number of MC within the walls of the seminiferous tubules; many of these cells were active and expressing tryptase (65). These MC were often localized near to spermatogonia and Sertoli cells, suggesting that MC might

\section{REFERENCES}

1. Maekawa M, Kamimura K, Nagano T. Peritubular myoid cells in the testis: their structure and function. Arch Histol Cytol (1996) 59(1):1-13. doi: 10.1679/aohc.59.1

2. Hirai S, Naito M, Terayama H, Qu N, Kuerban M, Musha M, et al. The origin of lymphatic capillaries in murine testes. J Androl (2012) 33(4):745-51. doi: 10.2164/jandrol.111.015156

3. Svingen T, Francois M, Wilhelm D, Koopman P. Three-dimensional imaging of Prox1-EGFP transgenic mouse gonads reveals divergent modes of lymphangiogenesis in the testis and ovary. PLoS One (2012) 7(12):e52620. doi: 10.1371/journal.pone.0052620

4. DeFalco T, Potter SJ, Williams AV, Waller B, Kan MJ, Capel B. Macrophages Contribute to the Spermatogonial Niche in the Adult Testis. Cell Rep (2015) 12(7):1107-9. doi: 10.1016/j.celrep.2015.07.015 affect spermatogonia that express PAR2, possibly via their secreted products (65).

\section{CONCLUSIONS AND FUTURE PERSPECTIVES}

Immune cells have essential roles in maintaining testicular homeostasis by dampening the inflammatory response and supporting normal physiological functions. The attenuated inflammatory response of testicular immune cells, particularly TM, is essential as the testis is an immune privileged organ. Any inflammatory response can severely damage testicular function - namely steroidogenesis and spermatogenesis. Although substantial progress has been made in understanding testicular immune cell function, more detailed investigations are now required to delineate the interactions between these immune cells and neighboring nonimmune cells. The mechanisms underlying how immune cells help to resolve inflammation and promote tissue repair are to be studied in depth. Advances in this area will improve our understanding of male infertility problems and will pave the way for the development of innovative therapeutics.

\section{AUTHOR CONTRIBUTIONS}

All authors contributed to the article and approved the submitted version.

\section{FUNDING}

The support of the Deutsche Forschungsgemeinschaft (DFG) for the International Research Training Group (GRK 1871/2-1) on 'Molecular pathogenesis of male reproductive disorders' and the Faculty of Medicine of the Justus-Liebig-University of Giessen is gratefully acknowledged. SB is supported by DFG (BH93/1-4). The support from the University of Buenos Aires and CONICET is greatly acknowledged.

5. Hedger MP. "The Immunophysiology of Male Reproduction," in Knobil and Neill's Physiology of Reproduction. Amsterdam, Netherlands (2015). p. 805-92.

6. Kitadate Y, Jorg DJ, Tokue M, Maruyama A, Ichikawa R, Tsuchiya S, et al. Competition for Mitogens Regulates Spermatogenic Stem Cell Homeostasis in an Open Niche. Cell Stem Cell (2019) 24(1):79-92 e6. doi: 10.1016/ j.stem.2018.11.013

7. Liu Y, Liang Y, Wang S, Tarique I, Vistro WA, Zhang H, et al. Identification and characterization of telocytes in rat testis. Aging (Albany NY) (2019) 11 (15):5757-68. doi: 10.18632/aging.102158

8. Marini M, Rosa I, Guasti D, Gacci M, Sgambati E, Ibba-Manneschi L, et al. Reappraising the microscopic anatomy of human testis: identification of telocyte networks in the peritubular and intertubular stromal space. Sci Rep (2018) 8(1):14780. doi: 10.1038/s41598-018-33126-2

9. Rosa I, Marini M, Sgambati E, Ibba-Manneschi L, Manetti M. Telocytes and lymphatic endothelial cells: Two immunophenotypically distinct and spatially 
close cell entities. Acta Histochem (2020) 122(3):151530. doi: 10.1016/ j.acthis. 2020.151530

10. Fijak M, Pilatz A, Hedger MP, Nicolas N, Bhushan S, Michel V, et al. Infectious, inflammatory and 'autoimmune' male factor infertility: how do rodent models inform clinical practice? Hum Reprod Update (2018) 24 (4):416-41. doi: 10.1093/humupd/dmy009

11. Zhao S, Zhu W, Xue S, Han D. Testicular defense systems: immune privilege and innate immunity. Cell Mol Immunol (2014) 11(5):428-37. doi: 10.1038/ cmi.2014.38

12. Arck P, Solano ME, Walecki M, Meinhardt A. The immune privilege of testis and gravid uterus: same difference? Mol Cell Endocrinol (2014) 382(1):509-20. doi: 10.1016/j.mce.2013.09.022

13. Bleriot C, Chakarov S, Ginhoux F. Determinants of Resident Tissue Macrophage Identity and Function. Immunity (2020) 52(6):957-70. doi: 10.1016/j.immuni.2020.05.014

14. Wang M, Fijak M, Hossain H, Markmann M, Nusing RM, Lochnit G, et al. Characterization of the Micro-Environment of the Testis that Shapes the Phenotype and Function of Testicular Macrophages. J Immunol (2017) 198 (11):4327-40. doi: 10.4049/jimmunol.1700162

15. Niemi M, Sharpe RM, Brown WR. Macrophages in the interstitial tissue of the rat testis. Cell Tissue Res (1986) 243(2):337-44. doi: 10.1007/BF00251049

16. Mossadegh-Keller N, Gentek R, Gimenez G, Bigot S, Mailfert S, Sieweke MH. Developmental origin and maintenance of distinct testicular macrophage populations. J Exp Med (2017) 214(10):2829-41. doi: 10.1084/jem.20170829

17. Chakarov S, Lim HY, Tan L, Lim SY, See P, Lum J, et al. Two distinct interstitial macrophage populations coexist across tissues in specific subtissular niches. Science (2019) 363(6432):1190-203. doi: 10.1126/ science.aau0964

18. Hoeffel G, Chen J, Lavin Y, Low D, Almeida FF, See P, et al. C-Myb(+) erythro-myeloid progenitor-derived fetal monocytes give rise to adult tissueresident macrophages. Immunity (2015) 42(4):665-78. doi: 10.1016/ j.immuni.2015.03.011

19. Bain CC, Bravo-Blas A, Scott CL, Perdiguero EG, Geissmann F, Henri S, et al. Constant replenishment from circulating monocytes maintains the macrophage pool in the intestine of adult mice. Nat Immunol (2014) 15 (10):929-37. doi: 10.1038/ni.2967

20. Shaw TN, Houston SA, Wemyss K, Bridgeman HM, Barbera TA, ZangerleMurray T, et al. Tissue-resident macrophages in the intestine are long lived and defined by Tim-4 and CD4 expression. J Exp Med (2018) 215(6):1507-18. doi: $10.1084 /$ jem. 20180019

21. Calderon B, Carrero JA, Ferris ST, Sojka DK, Moore L, Epelman S, et al. The pancreas anatomy conditions the origin and properties of resident macrophages. J Exp Med (2015) 212(10):1497-512. doi: 10.1084/ jem.20150496

22. Tamoutounour S, Guilliams M, Montanana Sanchis F, Liu H, Terhorst D, Malosse C, et al. Origins and functional specialization of macrophages and of conventional and monocyte-derived dendritic cells in mouse skin. Immunity (2013) 39(5):925-38. doi: 10.1016/j.immuni.2013.10.004

23. Schulz C, Gomez Perdiguero E, Chorro L, Szabo-Rogers H, Cagnard N, Kierdorf $\mathrm{K}$, et al. A lineage of myeloid cells independent of Myb and hematopoietic stem cells. Science (2012) 336(6077):86-90. doi: 10.1126/ science. 1219179

24. Lavin Y, Winter D, Blecher-Gonen R, David E, Keren-Shaul H, Merad M, et al. Tissue-resident macrophage enhancer landscapes are shaped by the local microenvironment. Cell (2014) 159(6):1312-26. doi: 10.1016/j.cell. 2014.11.018

25. van de Laar L, Saelens W, De Prijck S, Martens L, Scott CL, Van Isterdael G, et al. Yolk Sac Macrophages, Fetal Liver, and Adult Monocytes Can Colonize an Empty Niche and Develop into Functional Tissue-Resident Macrophages. Immunity (2016) 44(4):755-68. doi: 10.1016/j.immuni. 2016.02.017

26. Lukyanenko YO, Chen JJ, Hutson JC. Production of 25-hydroxycholesterol by testicular macrophages and its effects on Leydig cells. Biol Reprod (2001) 64 (3):790-6. doi: 10.1095/biolreprod64.3.790

27. Barakat B, O'Connor AE, Gold E, de Kretser DM, Loveland KL. Inhibin, activin, follistatin and FSH serum levels and testicular production are highly modulated during the first spermatogenic wave in mice. Reproduction (2008) 136(3):345-59. doi: 10.1530/REP-08-0140
28. Bhushan S, Tchatalbachev S, Lu Y, Frohlich S, Fijak M, Vijayan V, et al. Differential activation of inflammatory pathways in testicular macrophages provides a rationale for their subdued inflammatory capacity. J Immunol (2015) 194(11):5455-64. doi: 10.4049/jimmunol.1401132

29. Winnall WR, Muir JA, Hedger MP. Rat resident testicular macrophages have an alternatively activated phenotype and constitutively produce interleukin-10 in vitro. J Leukoc Biol (2011) 90(1):133-43. doi: 10.1189/jlb.1010557

30. Xia W, Wong EW, Mruk DD, Cheng CY. TGF-beta3 and TNFalpha perturb blood-testis barrier (BTB) dynamics by accelerating the clathrin-mediated endocytosis of integral membrane proteins: a new concept of BTB regulation during spermatogenesis. Dev Biol (2009) 327(1):48-61. doi: 10.1016/ j.ydbio.2008.11.028

31. Weissman BA, Niu E, Ge R, Sottas CM, Holmes M, Hutson JC, et al. Paracrine modulation of androgen synthesis in rat leydig cells by nitric oxide. J Androl (2005) 26(3):369-78. doi: 10.2164/jandrol.04178

32. Gerdprasert O, O’Bryan MK, Nikolic-Paterson DJ, Sebire K, de Kretser DM, Hedger MP. Expression of monocyte chemoattractant protein-1 and macrophage colony-stimulating factor in normal and inflamed rat testis. Mol Hum Reprod (2002) 8(6):518-24. doi: 10.1093/molehr/8.6.518

33. Rival C, Theas MS, Suescun MO, Jacobo P, Guazzone V, van Rooijen N, et al. Functional and phenotypic characteristics of testicular macrophages in experimental autoimmune orchitis. J Pathol (2008) 215(2):108-17. doi: 10.1002/path.2328

34. Bhushan S, Hossain H, Lu Y, Geisler A, Tchatalbachev S, Mikulski Z, et al. Uropathogenic E. coli induce different immune response in testicular and peritoneal macrophages: implications for testicular immune privilege. PLoS One (2011) 6(12):e28452. doi: 10.1371/journal.pone.0028452

35. Klein B, Bhushan S, Gunther S, Middendorff R, Loveland KL, Hedger MP, et al. Differential tissue-specific damage caused by bacterial epididymoorchitis in the mouse. Mol Hum Reprod (2020) 26(4):215-27. doi: 10.1093/ molehr/gaaa011

36. Rival C, Lustig L, Iosub R, Guazzone VA, Schneider E, Meinhardt A, et al. Identification of a dendritic cell population in normal testis and in chronically inflamed testis of rats with autoimmune orchitis. Cell Tissue Res (2006) 324 (2):311-8. doi: 10.1007/s00441-005-0129-5

37. Jarazo-Dietrich S, Jacobo P, Perez CV, Guazzone VA, Lustig L, Theas MS. Up regulation of nitric oxide synthase-nitric oxide system in the testis of rats undergoing autoimmune orchitis. Immunobiology (2012) 217(8):778-87. doi: 10.1016/j.imbio.2012.04.007

38. Perez CV, Theas MS, Jacobo PV, Jarazo-Dietrich S, Guazzone VA, Lustig L. Dual role of immune cells in the testis: Protective or pathogenic for germ cells? Spermatogenesis (2013) 3(1):e23870. doi: 10.4161/spmg.23870

39. Frungieri MB, Weidinger S, Meineke V, Kohn FM, Mayerhofer A Proliferative action of mast-cell tryptase is mediated by PAR2, COX2, prostaglandins, and PPARgamma : Possible relevance to human fibrotic disorders. Proc Natl Acad Sci U S A (2002) 99(23):15072-7. doi: 10.1073/ pnas. 232422999

40. Duan YG, Yu CF, Novak N, Bieber T, Zhu CH, Schuppe HC, et al. Immunodeviation towards a Th17 immune response associated with testicular damage in azoospermic men. Int J Androl (2011) 34(6 Pt 2):e53645. doi: $10.1111 / j .1365-2605.2010 .01137 . x$

41. Rodriguez MG, Rival C, Theas MS, Lustig L. Immunohistopathology of the contralateral testis of rats undergoing experimental torsion of the spermatic cord. Asian J Androl (2006) 8(5):576-83. doi: 10.1111/j.17457262.2006.00146.x

42. Zhang Y, Li N, Chen Q, Yan K, Liu Z, Zhang X, et al. Breakdown of immune homeostasis in the testis of mice lacking Tyro3, Axl and Mer receptor tyrosine kinases. Immunol Cell Biol (2013) 91(6):416-26. doi: 10.1038/icb.2013.22

43. Tarbell KV, Rahman K. Dendritic cells in autoimmune disease. In: Rose $\mathrm{N}$ and Mackay I, editors. The Autoimmune Diseases. 6th edition. London: Elsevier Inc. (2019). p. 213-23.

44. Guazzone VA, Hollwegs S, Mardirosian M, Jacobo P, Hackstein H, Wygrecka M, et al. Characterization of dendritic cells in testicular draining lymph nodes in a rat model of experimental autoimmune orchitis. Int J Androl (2011) 34(3):276-89. doi: 10.1111/j.1365-2605.2010.01082.x

45. Rival C, Guazzone VA, von Wulffen W, Hackstein H, Schneider E, Lustig L, et al. Expression of co-stimulatory molecules, chemokine receptors and proinflammatory cytokines in dendritic cells from normal and chronically 
inflamed rat testis. Mol Hum Reprod (2007) 13(12):853-61. doi: 10.1093/ molehr/gam067

46. Gao J, Wang X, Wang Y, Han F, Cai W, Zhao B, et al. Murine Sertoli cells promote the development of tolerogenic dendritic cells: a pivotal role of galectin-1. Immunology (2016) 148(3):253-65. doi: 10.1111/ imm. 12598

47. Gately MK, Renzetti LM, Magram J, Stern AS, Adorini L, Gubler U, et al. The interleukin-12/interleukin-12-receptor system: role in normal and pathologic immune responses. Annu Rev Immunol (1998) 16:495-521. doi: 10.1146/ annurev.immunol.16.1.495

48. Guazzone VA, Rival C, Denduchis B, Lustig L. Monocyte chemoattractant protein-1 (MCP-1/CCL2) in experimental autoimmune orchitis. $J$ Reprod Immunol (2003) 60(2):143-57. doi: 10.1016/j.jri.2003.08.001

49. Guazzone VA, Jacobo P, Denduchis B, Lustig L. Expression of cell adhesion molecules, chemokines and chemokine receptors involved in leukocyte traffic in rats undergoing autoimmune orchitis. Reproduction (2012) 143(5):651-62. doi: 10.1530/REP-11-0079

50. Khan U, Ghazanfar H. T Lymphocytes and Autoimmunity. Int Rev Cell Mol Biol (2018) 341:125-68. doi: 10.1016/bs.ircmb.2018.05.008

51. Jacobo P, Guazzone VA, Jarazo-Dietrich S, Theas MS, Lustig L. Differential changes in CD4+ and CD8+ effector and regulatory T lymphocyte subsets in the testis of rats undergoing autoimmune orchitis. J Reprod Immunol (2009) 81(1):44-54. doi: 10.1016/j.jri.2009.04.005

52. Jacobo P, Perez CV, Theas MS, Guazzone VA, Lustig L. CD4+ and CD8+ T cells producing Th1 and Th17 cytokines are involved in the pathogenesis of autoimmune orchitis. Reproduction (2011) 141(2):249-58. doi: 10.1530/REP10-0362

53. Jacobo PV, Fass M, Perez CV, Jarazo-Dietrich S, Lustig L, Theas MS. Involvement of soluble Fas Ligand in germ cell apoptosis in testis of rats undergoing autoimmune orchitis. Cytokine (2012) 60(2):385-92. doi: 10.1016/j.cyto.2012.07.020

54. Wheeler K, Tardif S, Rival C, Luu B, Bui E, Del Rio R, et al. Regulatory T cells control tolerogenic versus autoimmune response to sperm in vasectomy. Proc Natl Acad Sci U S A (2011) 108(18):7511-6. doi: 10.1073/pnas.10176 15108

55. Nicolas N, Michel V, Bhushan S, Wahle E, Hayward S, Ludlow H, et al. Testicular activin and follistatin levels are elevated during the course of experimental autoimmune epididymo-orchitis in mice. Sci Rep (2017) 7:42391. doi: 10.1038/srep42391

56. Jacobo P. The role of regulatory T Cells in autoimmune orchitis. Andrologia (2018) 50(11):e13092. doi: 10.1111/and.13092
57. Jacobo P, Guazzone VA, Perez CV, Lustig L. CD4+ Foxp3+ regulatory T cells in autoimmune orchitis: phenotypic and functional characterization. Am J Reprod Immunol (2015) 73(2):109-25. doi: 10.1111/aji.12312

58. Tung KS, Harakal J, Qiao H, Rival C, Li JC, Paul AG, et al. Egress of sperm autoantigen from seminiferous tubules maintains systemic tolerance. J Clin Invest (2017) 127(3):1046-60. doi: 10.1172/JCI89927

59. Mechlin C, Kogan B. Mast cells, estrogens, and cryptorchidism: a histological based review. Transl Androl Urol (2012) 1(2):97-102. doi: 10.3978/j.issn.22234683.2012.06

60. Krystel-Whittemore M, Dileepan KN, Wood JG. Mast Cell: A MultiFunctional Master Cell. Front Immunol (2015) 6:620. doi: 10.3389/ fimmu.2015.00620

61. Haidl G, Duan YG, Chen SJ, Kohn FM, Schuppe HC, Allam JP. The role of mast cells in male infertility. Expert Rev Clin Immunol (2011) 7(5):627-34. doi: $10.1586 /$ eci.11.57

62. Moreno D, Sobarzo CM, Lustig L, Rodriguez Pena MG, Guazzone VA. Effect of ketotifen fumarate on experimental autoimmune orchitis and torsion of the spermatic cord. Asian J Androl (2020) 22(1):112-7. doi: 10.4103/aja.aja_30_19

63. Acikgoz A, Asci R, Aydin O, Cavus H, Donmez G, Buyukalpelli R. The role of ketotifen in the prevention of testicular damage in rats with experimental unilateral undescended testes. Drug Des Devel Ther (2014) 8:2089-97. doi: 10.2147/DDDT.S67941

64. Iosub R, Klug J, Fijak M, Schneider E, Frohlich S, Blumbach K, et al. Development of testicular inflammation in the rat involves activation of proteinase-activated receptor-2. J Pathol (2006) 208(5):686-98. doi: 10.1002/path.1938

65. Mayerhofer A, Walenta L, Mayer C, Eubler K, Welter H. Human testicular peritubular cells, mast cells and testicular inflammation. Andrologia (2018) 50 (11):e13055. doi: 10.1111/and.13055

Conflict of Interest: The authors declare that the research was conducted in the absence of any commercial or financial relationships that could be construed as a potential conflict of interest.

Copyright $\odot 2020$ Bhushan, Theas, Guazzone, Jacobo, Wang, Fijak, Meinhardt and Lustig. This is an open-access article distributed under the terms of the Creative Commons Attribution License (CC BY). The use, distribution or reproduction in other forums is permitted, provided the original author(s) and the copyright owner(s) are credited and that the original publication in this journal is cited, in accordance with accepted academic practice. No use, distribution or reproduction is permitted which does not comply with these terms. 